\title{
The Behavior of Elevated Water Tanks under Impact Loading
}

\author{
Davoud Tavakoli ${ }^{*}$, Ali Ahmadi ${ }^{1}$ \\ ${ }^{1}$ Department of Civil Engineering, Shahrekord branch, Islamic Azad University, Rahmatieh, 88146, Shahrekord, Islamic Republic of Iran \\ * Corresponding author, e-mail: d.tavakoli@sru.ac.ir
}

Received: 10 May 2021, Accepted: 26 May 2021, Published online: 10 June 2021

\begin{abstract}
Because of the crucial role of elevated water tanks and their various uses, it is necessary to evaluate their structural behavior under threats to improve the durability performance of such tanks without putting them in jeopardy. In the present research, three open cylindrical concrete water tanks were modeled under an impact load (aerial blast) with the weight of $100 \mathrm{~kg}$ TNT explosive charge. The tanks were modeled in 3 forms: slender, middle, and broad (Aspect ratio $=1.28,1$ and 0.85). Each tank contained various levels of water (non-water, half water, and full water) to estimate their structural behavior under blast loading. Moreover, the CEL (Coupled Eulerian-Lagrangian) approach was used to simulate water structure interaction in finite element program. For a comprehensive analysis of the structural behavior of water tanks, LRB (Lead rubber bearing) isolator device was also used to observe the effect of isolator under blast loading on elevated water tanks in all models. The results of this study show that the water level leads to stiffness of the structures that cause better performance under blast loading and also the intersection of the shaft and concrete column would be the critical section of this structure under blast loading. It is also concluded that Stress and Strain decrease as the water tanks level increase and stiffen (up to $33 \%$ ). Also, it is noticeable that the existence of the isolator has deteriorated the results because of the decreases in the structure's stiffness and the increase of the displacements.
\end{abstract}

Keywords

elevated concrete tank, impact loading, CEL approach, finite element method

\section{Introduction}

According to the crucial role of water tanks and the country's geographical and strategic location, which is at the constant threat of aerial and terrorist attacks, building a passive defensive system for water tanks must be taken into consideration. Since little research has been done about the vulnerability of water tanks against blasting loads, doing further studies on this topic is an important matter to consider

As the population grows and cities expand, water tanks are increasingly being used to meet the needs of the urban water supply network. The presence of water in elevated water tanks with different structural behavioral properties from the structural behavior of most of the ordinary water tanks complicate such tanks [1].

\section{Research background}

Earlier studies about the analytical and experimental observations of rigid rectangular tanks were done by Hoskins and Jacobsen [2] with a simulation model of a horizontal earthquake. Subsequently, in another study done by Graham and Rodriguez [3], the fluid version in a rectangular vessel much like the mass-and-spring model was used. Hamdan [4] was one of the first researchers who observed the dynamic behavior of water tanks. Later, Haroun [5] proposed a similar method for calculating the distribution of pressure and height of liquid surface waves in cylindrical and rectangular tanks under the influence of horizontal oscillation.

The Haroun method has been used a lot in related studies since then [6]. Melerski [7] used an efficient numerical technique for the analysis of environmental outcomes (heat, contraction, and swelling) in thin-walled concrete cylindrical tanks, for the storage of liquids under axis symmetric conditions. Kianoush and Chen [8] carried out a parametric observation. That the flexibility of the tank wall should be taken into consideration whilst calculating the hydrodynamic pressure. Kianoosh and Chen also [8] examined the dynamic behavior of open cylindrical water tanks above ground level. The main focus of their study waste identify the principle parameters affecting the 
dynamic behavior of structures and to prevent the interaction among those parameters. They concluded that the design techniques for calculating hydrodynamic pressure are too conservative.

Analysis about blasts was done in the previous centuries. Early analysis by recreational methods dates back to the $13^{\text {th }}$ and $14^{\text {th }}$ centuries. In 1999 , Hopkinson proposed a scale rule (law) for simple blasts that did not have a mathematical basis but was very important in practice [9]. He claimed that if a building was built with the same shape and materials but in different sizes and then exploded, the number of explosives needed to create similar effects would be directly proportional to the third power of the building's dimensions. This law was fully enacted in 1926 by Granz. Taylor was a scientist whose studies of the dynamics of explosive waves caused by explosives played a major role in the development of the British Ministry of Defense Research Center between 1936 and 1950 [10].

At first, he was doing research on propagation and depreciation of blast waves from conventional weapons, but later he changed his focus to studies related to the behavior of blast waves caused by the first atomic explosion in New Mexico [11]. Kalateh [12]investigated the dynamic failure of the concrete dams (gravity and arch) under blast. Moradi et al. [13] another researcher also did research on a similar subject. He studied underwater blast loading on the Karaj arch concrete dam and concluded that due to the significant standoff distance of the explosion, the dam's behavior was linear and with no damage to the body of the dam. A numerical and experimental investigation of the damage of a cylindrical shell full of water under blast load was done by Gao et al. [14] and Clubley [15]. By that investigation, it was understood that the water enhances the deformation.

However, the purpose of the present study is to analyze the explosive loading on the concrete water tank, which few researches have been done on it so far. Further issues will be discussed in the section part.

Pandey et al. [16] tested the effect of blast outside the outer shell of a reinforced concrete. In this paper, a parametric study as, well as the critical distance study for external blasts with different values of explosive has been done. Asgarpour [17] performed research on the subject of soilstructure-fluid interaction in reinforced concrete tanks. The tank was put into the ground under external blast loading. The result of the study shows that during earthquakes and blasts, the failure rate of the tank construction, without soil-structure interaction, is better than when the tank is placed on flexible soil, and this effect is more intense in soft soil than in stiff soil. However, Things are different with soil-structure interaction. The failure rate of tank construction under the blast load in stiff soil is better than in soft soil, and under the earthquake load, the opposite is true. Chaman [18] additionally studied the resilience of steel oil tanks against explosive and non-explosive and Rostaye [19] studied the overall performance of steel tanks under blast loads. Zhou et al. [20] have conducted experimental studies about the deformation of tanks caused by blast loading. It was concluded that the behavior of water tanks will enhance if the wall thickness increase.

Li et al. [21] studied the dynamic response of liquid in the cabin under internal blast loading. They used both experimental and numerical studies. By implementing these methods, they concluded that internal blast causes high pressure shock. Besides, they observed that liquid decreases the damage of plates.

Zhang et al. [22] investigated a large LNG storage tanks under blast loading. They implemented ALE algorithm for spreading blast wave and also fluid-solid coupling theory. They observed that blast causes a significant damage to the center of the LNG storage tanks and the outer structure of the tank was damaged more.

Chen et al. [23] conducted research on arch-roof of atmospheric oil tanks subjected to blast waves. In their studies, two simulation software such as ANSYS and LS-DYNA were used for blasting. It was found out that the peak values of displacements, stresses and, etc. are significantly higher than values subjected to a single blast wave.

As mentioned in the previous section, the behavior of the concrete tanks under blast loading is one of the important issues that has not been addressed properly. So the aim of the current paper is to analyze the behavior of concrete tanks and also observe the damage and critical parameters like sloshing wave and stress that bring about significant damage to them under blast loading with empty, semifilled, and filled model to analyze the effect of water on these structures as well. Nowadays, isolators are used a lot and that is because of their flexibility and displacement control. As a part of the study, the behavior of the elevated water tanks equipped with LRB isolators under blast loading was also scrutinized for the first time. It is worth mentioning that in some cases, the blast loading causes motion in the ground and effects like seismic loading. As our blast reference point is above the ground, the mentioned effect would be negligible. 


\section{Modeling}

\subsection{Behavioral pattern of concrete}

To introduce non-linear concrete behavior a plastic concrete model which can show non-linear behavior and breakdown properties of brittle materials such as concrete has been used in both static and dynamic analysis. And it is assumed that tensile cracks and compression fractures are the two main aspects of the rupture in mechanism concrete, and for fracture modeling, brittle materials are designed under cyclic loads (alternating tension and pressure), so that it is difficult to recover during reciprocating loads.

In this study, an isotropic damage model has been used in the linear range, and by combining isotropic traction and plastic pressure the nonlinear behavior of concrete has been shown.

By examining this model, it is assumed that the response to single-axis traction and pressure is controlled by the plastic failure criterion shown in Figs. 1 and 2. They change linearly, which is associated with the onset and expansion of fine cracks in the concrete. After passing through the point $\sigma_{t 0}$, the damage appears invisible cracks forms, which are shown as a softening curve in the stress-strain space $\sigma_{c 0}$.

The tensile damage parameter $\left(d_{t}\right)$ is used to show the effect of reducing in tensile strength, so within the n cycle, the decreased stiffness associated with the identical cycle is calculated from Eq. (2) [24]:

$$
\begin{aligned}
& d_{t}=1-\left(\frac{\sigma_{t}}{\sigma_{t 0}}\right), \\
& E_{t}=\left(1-d_{t}\right) E .
\end{aligned}
$$

The tensile stress-strain diagram of concrete is obtained by using the post-yield equations of concrete that have been exposed to tension. These equations are suggested

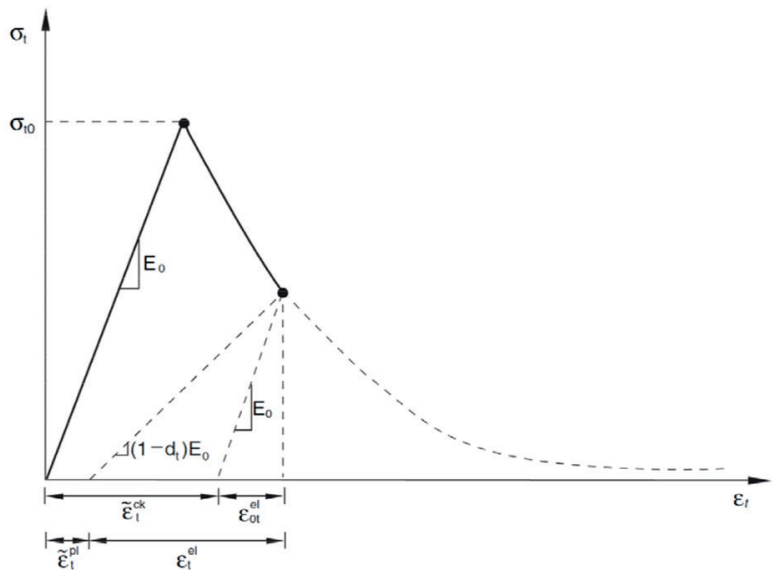

Fig. 1 Concrete response under axial tensile load [24] by considering tensile stiffness, tensile softness, and interaction between bars and concrete. To determine the graph, it is needed to specify the parameters $\varepsilon_{o}, \sigma_{t}, \varepsilon_{t c k}$, dt that represent the tensile modulus, tensile strength, fracture strain, and yield parameter, respectively. The strain of yield is obtained from Eq. (3):

$\varepsilon_{t}^{c k}=\varepsilon_{t}-\varepsilon_{o t}^{e l}$.

$\varepsilon_{o t}^{e l}=\frac{\sigma_{t}}{E_{o}}$ equation sindicates the stress-strain of the damaged material and $\varepsilon t$ the overall stress-strain [24].

The Stiffness reduction effect is also introduced as a parameter of $d_{C}$ compression damage parameter. Thus, by defining the damage parameter in terms of compressive stress, according to Eq. (4) in then cycle, the reduced stiffness corresponding to the same cycle of Eq. (5) is calculated.

$d_{c}=1-\left(\frac{\sigma_{c 0}}{\sigma_{c u}}\right)$

$E_{n}=\left(1-d_{c}\right) E$

The stress-strain diagram of concrete in Figs. 1 and 2 is plotted using the equations after the yield of the concrete that has been subjected to single-axis pressure.

To use post-yield concrete equations, the parameters $\sigma c, \varepsilon c i n$, dc must first be determined to indicate the maximum compressive stress, non-tensile strain, and concrete yield parameter, respectively. Non-elastic strain is obtained from Eq. (6).

$\varepsilon_{c}^{i n}=\varepsilon_{c}-\varepsilon_{o c}^{e l}$

$\varepsilon_{o c}^{e l}=\frac{\sigma_{c}}{E_{t}}$ indicates the stress-strain of undamaged materials and $\varepsilon \mathrm{c}$ indicates the overall stress-strain [24].

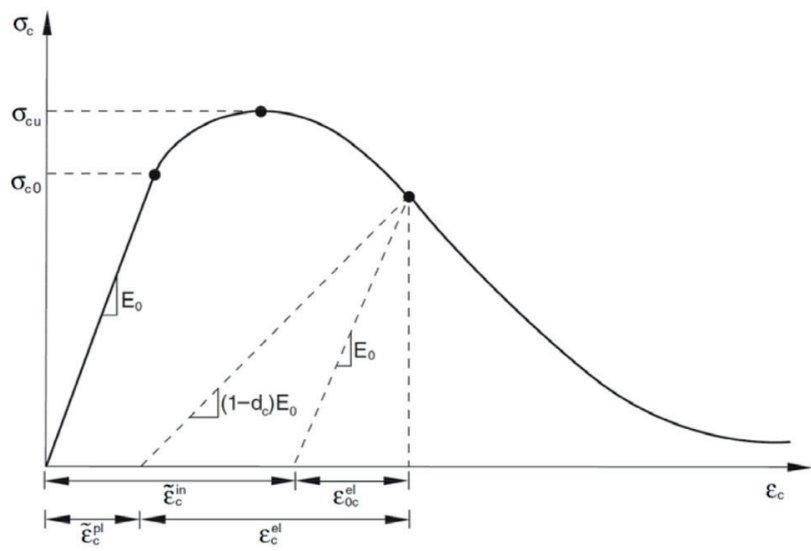

Fig. 2 Concrete reaction diagram under axial compressive loading [24] 


\subsection{Determination of wave parameters as a result of the explosion in the air}

Blast loading is certainly one of the most important forms of dynamic loading on elevated water tanks. Due to its fastness, this loading influences the structure of such tanks, which is not visible in other types of dynamic loading. In an aerial blast, the location of the blast is at a height above the ground level and a horizontal distance from the structure which the shock wave hits the ground before hitting the structure reflected and amplified [25]. Up to a horizontal distance from the blast source, there's a regular reflection and then a Mach reflection will occur, and the Mach wave's front is formed. To calculate the scaled distance from the blast wave [26], Eq. (7) is utilized in which:

$$
Z=\frac{R}{W^{\frac{1}{3}}}
$$

$R$ and $W$, respectively, are the distance of the desired point to the center of the blast source in terms of meters and the weight of TNT is equivalent to the blast substance in kilograms.

To calculate the overpressure, various experimental and analytical relations such as Brode's equation were used [26]: If $P_{s}>10$ bar as a result (near field):

$$
P_{s}(\text { bar })=\frac{6.7}{Z^{3}}+1
$$

If $0.1<P_{s}<10$ bar (far field):

$$
P_{s}(\text { bar })=\frac{0.975}{Z}+\frac{1.455}{Z^{2}}+\frac{5.85}{Z^{3}}-0.019 \text {. }
$$

It is also possible to use, use Henrich equations for calculating maximum static pressure (resulting from analytical relations) [27]:

$P_{s}($ bar $)=\frac{17.072}{Z}+\frac{5.540}{Z^{2}}+\frac{0.357}{Z^{3}}+\frac{0.00625}{Z^{4}} 0.05 \leq Z \leq 0.3$

$P_{s}($ bar $)=\frac{6.194}{Z}-\frac{0.326}{Z^{2}}+\frac{2.132}{Z^{3}} 0.3 \leq Z \leq 1$

$P_{s}($ bar $)=\frac{0.662}{Z}-\frac{4.05}{Z^{2}}+\frac{3.288}{Z^{3}} 1 \leq Z \leq 10$

For the pressure resulting from the explosion before hitting the tanker ground, and also the reflected pressure, at any distance from the blast site, a pressure-time diagram can be drawn according to Figs. 3 and 4 .

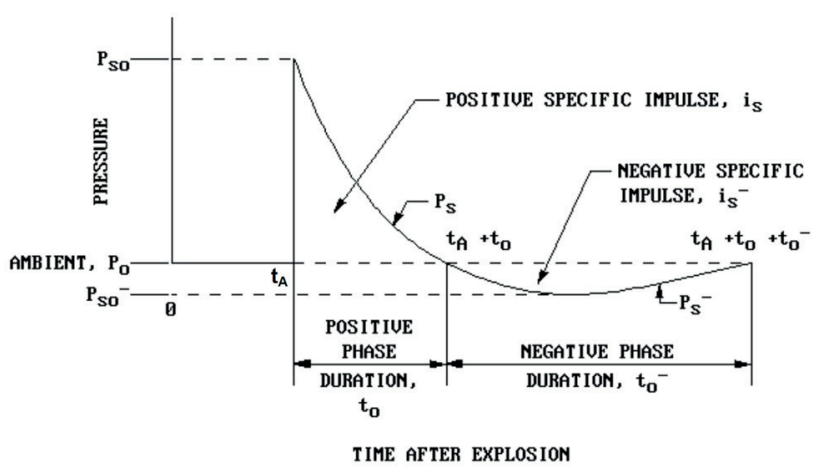

Fig. 3 Ideal history of Pressure-Time graph of blast wave [27]

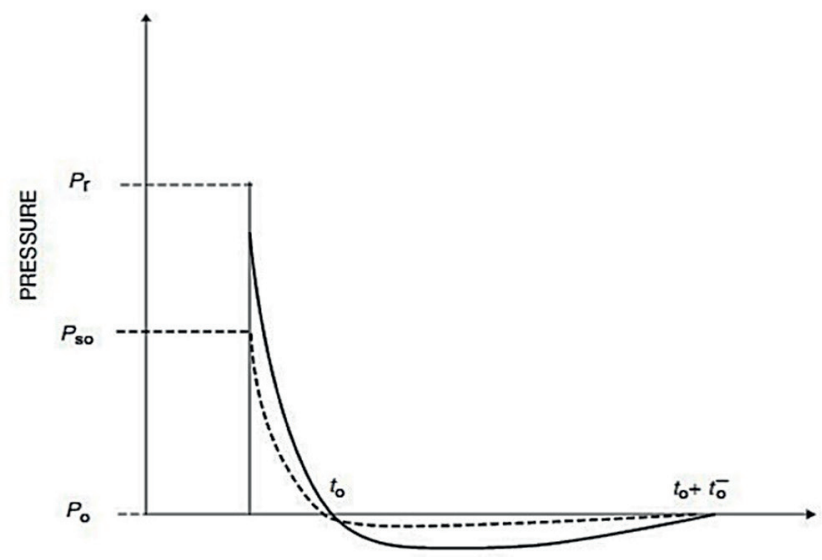

Fig. 4 Pressures-Time graph of in incident and reflected wave [27]

\subsection{Structural modeling}

In general, the techniques for handling the problem of solid and fluid interaction are divided into the three essential following groups[28].

- Added mass method, (virtual mass method)

- Euler-Lagrange method,

- Lagrange-Lagrange method

In the present finite element model, the Couple-Euler Lagrangian method has been used. In this method, the steel tank is considered as Lagrangian environment and the water inside the tank is considered as Euler domain. The finite element model construction includes three-dimensional elements with reduced integration (EC3D8R) and three-dimensional 10 node elements C3D10M. To examine the interaction between the tank and the liquid general contact without friction coefficient was used.

The dynamic structural behavior of the tank in the present study has been examined under blast load. To simulate the blast load in Abaqus software, the CONWEP method, which calculates the specific load of a certain amount of TNT at a certain distance from the structure has been used. 
In this study, a blast in the open air, which is the most critical type of explosive load for the elevated water tank, has been used. For analyzing the explosive load at a certain distance, the dynamic response of the structure has been investigated.

The concrete water tank is modeled with Abaqus software and CONWEP method loading (Fig. 5). In this modeling, the nonlinear behavior of reinforced concrete tank has been defined. The compressive strength of concrete is $30 \mathrm{MPa}$. The tanks were under TNT explosive charge. The distance between the blast site and the ground was 30 meters and its distance to the tank was also 10 meters. In order to evaluate the behavior of the tanks, they were used in 3 forms such as slender, middle, and broad and they were modeled with fill, empty, and half water for the investigation effect of elevated water tanks (Table 1). The behavior of the LRB isolator can be seen in Fig. 6 [30].

To verify the models, the results of our modeling in ABAQUS have been compared with the experimental results which were used in Paija and Vahora [29] paper and their results were similar to ours to some extent but there were no other similar experiments.. In this study, an elevated steel water tank model was subjected to blast loading to observe the response of displacements, stresses, and the reaction of the water level and also the external blast load in different distances. To verify the results, the base

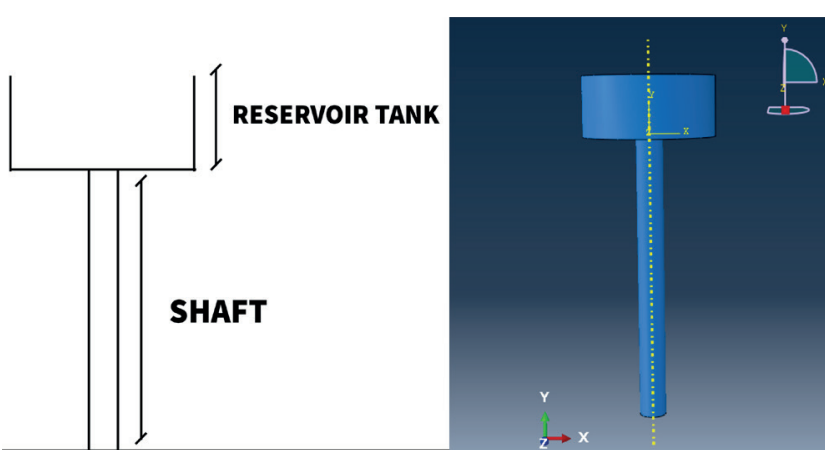

Fig. 5 Model of water tank reaction of the tank FX was observed. The results were $143840 \mathrm{KN}$ for frame 1 and $159417 \mathrm{KN}$ for frame 2 and there was approximately 2 percent difference between the two frames which shows there is a good match.

\section{Results and discussion}

In the present paper, the effect of blast loading on elevated water tanks with different levels of water (non-water, 50 $\%$, and $100 \%$ ) and also various forms of tanks (Slender, Middle, and Broad) was investigated. For better understanding, the results were divided into Displacement, Stress, Strain and Force section.

\subsection{Displacement}

As sloashing wave is one of the most important parameters that can damege the structures of elevated water tanks the displacements of fluid are shown in Figs. 7 and 8.

Fig. 7 reveals some significant differences between the two types of models, regarding the displacement of water.

In model M3, there is the most displacement of water when the tank is half full and with the same condition, the difference between models M1 to M3 is less marked. However, the gap between the water displacement of models M1-M3 and models 4-6 had become larger. A more detailed look at the bar chart M4-M6 reveals that the

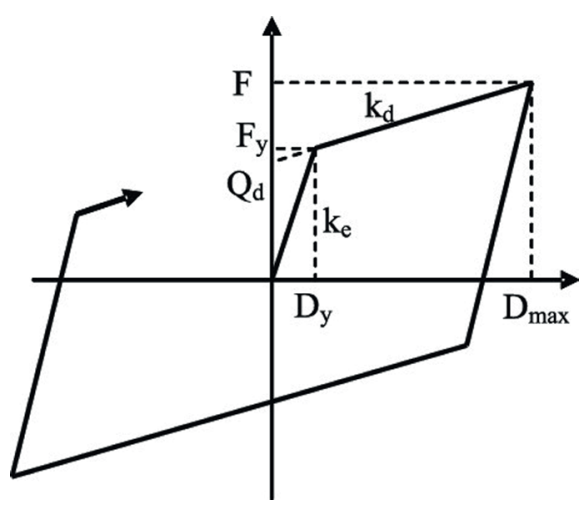

Fig. 6 Bilinear Behavior of LRB Isolator [30]

Table 1 Specification of models

\begin{tabular}{|c|c|c|c|c|c|c|c|c|c|c|c|}
\hline \multirow[b]{2}{*}{ models } & \multirow{2}{*}{$\begin{array}{l}\text { Aspect } \\
\text { ratio }\end{array}$} & \multicolumn{3}{|c|}{ Reservoir of tanks } & \multicolumn{3}{|c|}{ shaft } & \multicolumn{4}{|c|}{ Isolator parameters } \\
\hline & & $\begin{array}{l}\text { Thickness } \\
\text { (m) }\end{array}$ & $\begin{array}{l}\text { Diameter } \\
(\mathrm{m})\end{array}$ & $\begin{array}{l}\text { Height } \\
\text { (m) }\end{array}$ & $\begin{array}{l}\text { Thickness } \\
\text { (m) }\end{array}$ & $\begin{array}{l}\text { Diameter } \\
(\mathrm{m})\end{array}$ & $\begin{array}{l}\text { Height } \\
\text { (m) }\end{array}$ & $\begin{array}{l}\text { Shear Modulus } \\
\text { (Mpa) }\end{array}$ & $\begin{array}{l}\text { Poisson } \\
\text { ratio }\end{array}$ & $\begin{array}{l}\text { density } \\
\left(\mathrm{kg} / \mathrm{m}^{3}\right)\end{array}$ & $\begin{array}{c}\text { Elastic } \\
\text { Modulus (Mpa) }\end{array}$ \\
\hline M1 & 1.28 & 0.3 & 14 & 9 & 0.5 & 3 & 30 & - & - & - & - \\
\hline M2 & 1 & 0.3 & 14 & 7 & 0.5 & 3 & 30 & - & - & - & - \\
\hline M3 & 0.85 & 0.3 & 14 & 5.95 & 0.5 & 3 & 30 & - & - & - & - \\
\hline M4 & 1.28 & 0.3 & 14 & 9 & 0.5 & 3 & 30 & 0.272 & 0.499 & 960 & 0.0815 \\
\hline M5 & 1 & 0.3 & 14 & 7 & 0.5 & 3 & 30 & 0.272 & 0.499 & 960 & 0.0815 \\
\hline M6 & 0.85 & 0.3 & 14 & 5.95 & 0.5 & 3 & 30 & 0.272 & 0.499 & 960 & 0.0815 \\
\hline
\end{tabular}




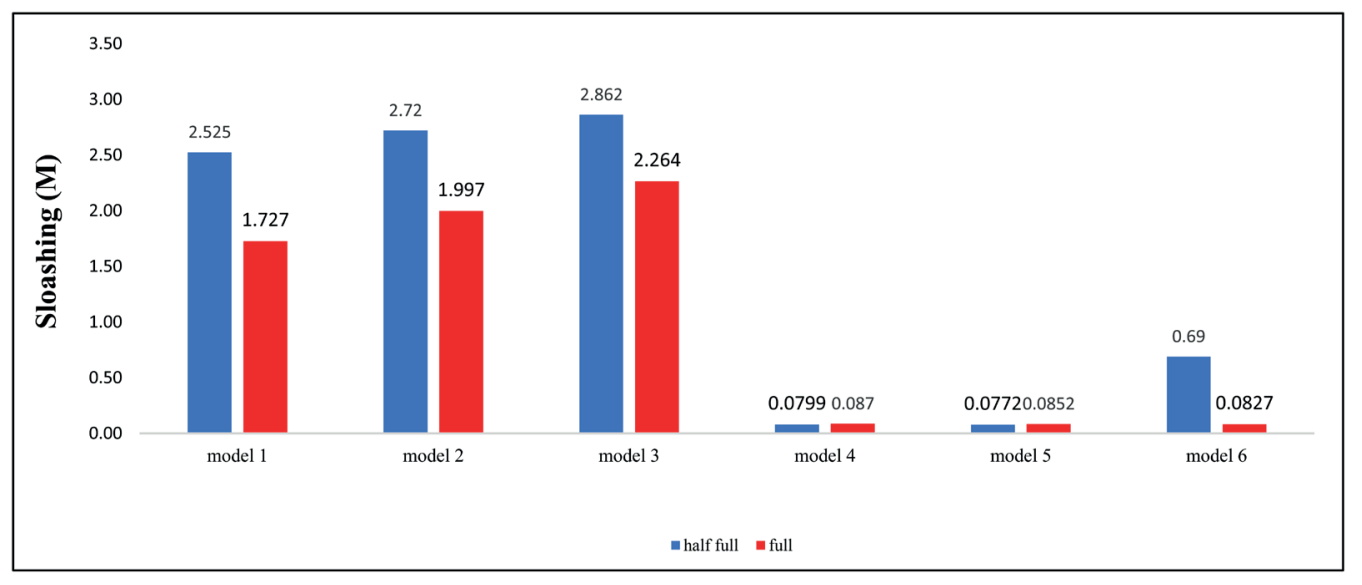

Fig. 7 Sloashing height of tanks

overall growth in the amount of water displacement was not always steady and model 6 had reached its highest value among the models with isolator when the tank is half full.

The displacement of water in a semi-filled model $(2.53 \mathrm{~m}$ for slender tank, $2.72 \mathrm{~m}$ for middle tank, and $2.86 \mathrm{~m}$ for broad tank) is more than the filled models $(1.73 \mathrm{~m}$ for slender tank, $2 \mathrm{~m}$ for middle tank, $2.26 \mathrm{~m}$ for broad tank) and as the aspect ratio increases the displacement of water decreases. As a result, it can be said that the sloshing wave height in filled-models is approximately $30 \%$ lower than semi-filled models. This is because the water in semi-filled model can move widely compared with the full model that water pours out from the tank.

In models 4, 5, and 6, as can be seen in Fig. 8, the displacements of tanks decrease as the water level increase. (decreasing of $90 \%$ in Sloashing heights in these models in comparison with non-lrb models was seen). As was mentioned in the related papers before [14, 15, 18, 20, 22], the structures with the higher stiffness can respond better than the models with lower stiffness. While the use of isolator causes the flexibility of structures, these results are predictable. Also, the sloashing height of the water is almost the same as the displacements of tanks, because of the isolator (Fig. 8).

The Sloshing heights of the full and semi-full tanks are also seen clearly in Fig. 9 According to this figure, the maximum of sloashing would appear at the edge of the highest level of elevated water tank. It is also noticeable that for M4, M5, and M6 the figures are similar. Therefore, in summary.Tthe non-isolator models were defined. As it can be seen in the Figs. 8 to 9, the maximum sloashing heights have occurred in the contact surface of water and tank shaft. So, the probability of the water overflow is increased and should be taken into consideration for the design of these structures.

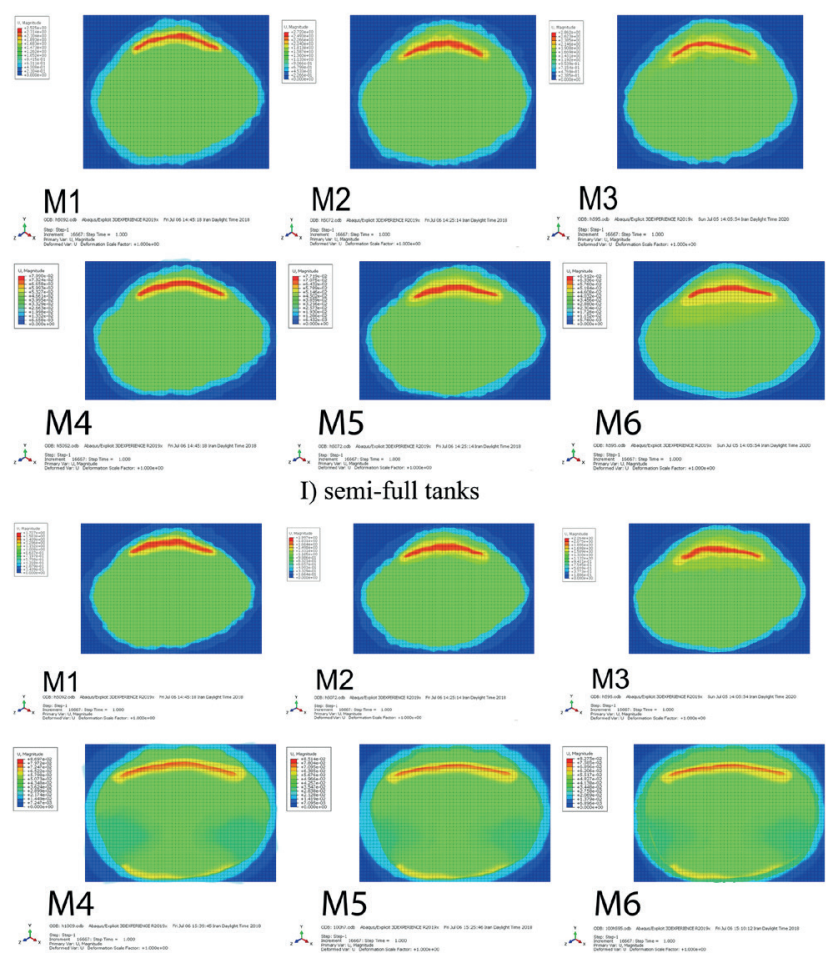

II) fulltanks

Fig. 8 Sloashing heights of I) semi-full II) full tanks
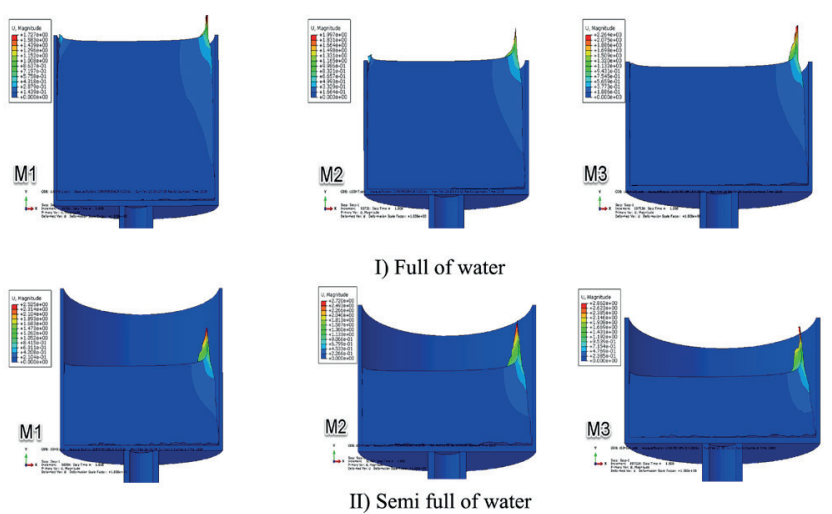

Fig. 9 Sloshing heights of full tanks 
Similarly, it can be stated that the displacement of tanks in filled models, except for the slender tank, is less than half-full and empty models, respectively (Fig. 10).

Fig. 10 demonstrates the displacement value of tanks concerning their specific characteristics. The bar charts are utilized to illustrate the tank condition, and there are three positions regarding the tanks. The tanks had been used in 3 forms full, half full.

By looking at the chart, it can be seen that the models M4-M6 by far provide the highest amount of displacement when the tank is empty and interestingly at just $1.20 \mathrm{~m}$ value.

As it is obvious, there is a considerable gap between the models with isolators and the models without an isolator. The models M1-M3 seem to provide almost a similar amount of displacement while the tank is likely to have more displacement in models M3-M6 when they are empty. Besides, the lowest amount of displacement is $4.53 \mathrm{~m}$, which is related to the broad model without an isolator.

Decreasing of the displacements and deformation of water tanks due to the water level indicates that water can have a significantly positive effect. In the blast resistance design, the deformation of the structure and its members is usually related to the ductility ratio in ASCE and UFC codes [31-33]. The possible reason is that the equivalent SDOF method is used in these design guidelines and the stress and strain information is harder to be extracted as compared to the deformation. On the contrary, the displacements of the tanks compared with non-isolator in models 4, 5, and 6 (both in semi- and full-filled models) are increased up to 80 , and as the aspect ratio increases, the displacements of the tanks also increase.

\subsection{Stress}

Fig. 11 shows the stress magnitude of the tank indifferent models. According to the bar charts, the models are categorized into two groups. In group 1 there are M1-M3 models which are without isolator, while in group 2 there areM4-M6 models that have isolator, and it is clear that the tension value in the tanks with isolator are is different from the tanks that do not have any isolator. In other words, models M4-M6 generally have more tension value.

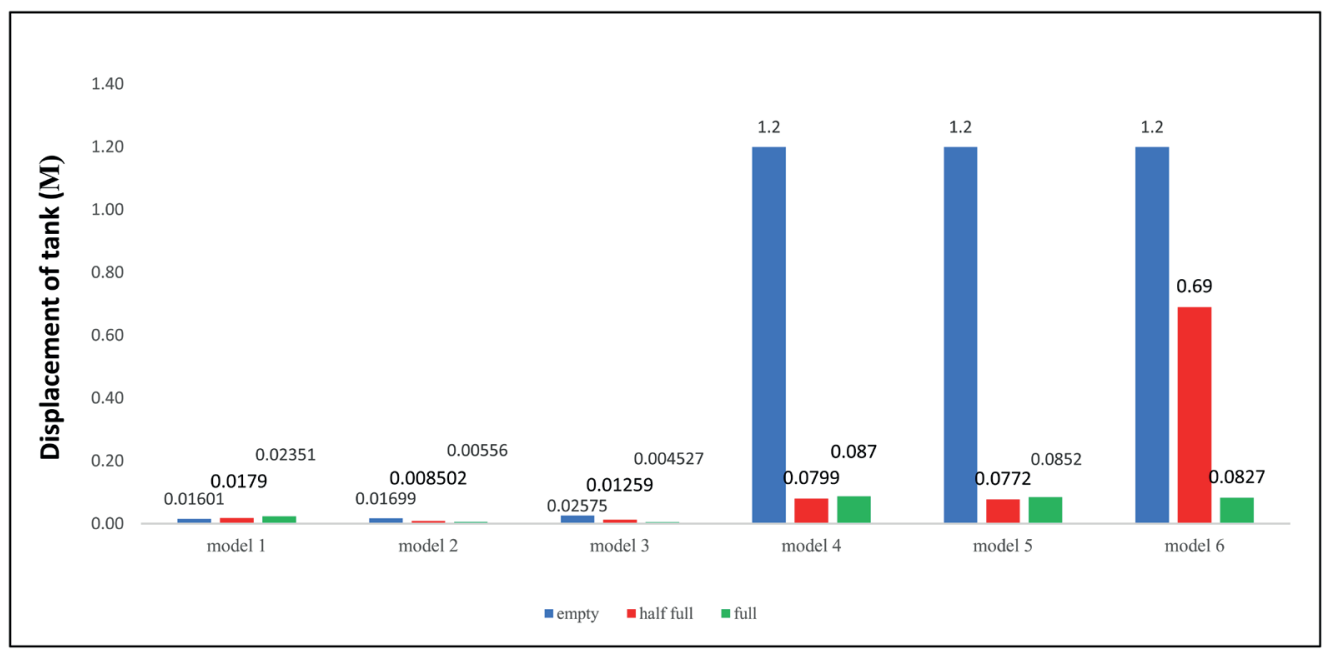

Fig. 10 Displacements of tanks

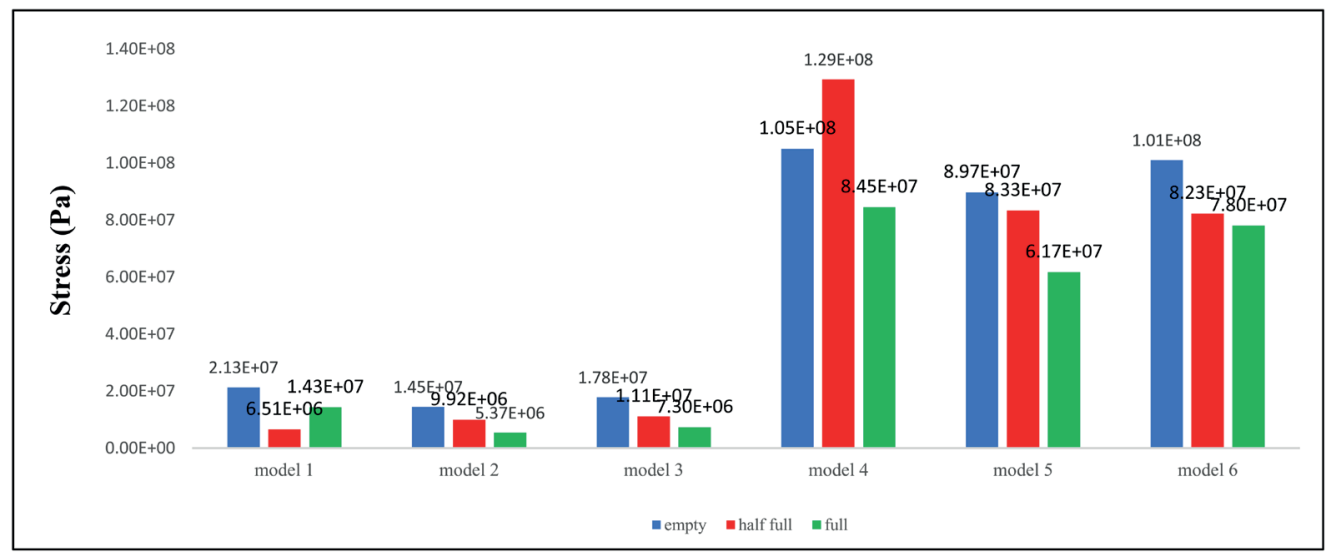

Fig. 11 Stresses of water tanks 
In model 4, when the tank is half full (just a little over $1.2 \mathrm{E}+08)$, the tension rate is interestingly at its highest rate. The green bar chart for model M2 indicates the lowest amount of tension value, which means that the full tank without an isolator is less likely to generate tension. Clearly, model M1 shows the maximum tension value, when the tank is empty and this is the highest value among the models with isolator.

\subsection{Strain}

In Fig. 12, the tank strain magnitude of each model with respect to their particular features has been compared. By looking at the strain magnitude carefully, it is understood that the model M4 has the highest value when the tank is empty, and according to the red bars, this value seems to be almost steady with a slight difference in models M5 and M6. However, it is clear that the models M4 to M6 almost indicate the same value, when the tanks are full. Similarly, such a thing has also occurred between models 5 and 6 , when the tank is half full, and has also the same condition. More significant growth in the strain value of model 4 has been seen.

By scrutinizing the chart it is revealed that the overall growth in strain amount can be negligible for models M1 to M3. For instance, model 1 shows a 4.25E3 amount of strain when the tank is half full and this amount has reached its lowest value in model 3 when the tank is full.

It can be concluded that strain and tension damage formal cases (M1, M2, and M3) in slender tank are more than middle and broad tank (because of the stiffnesses of the tanks) and the tension damage decreases as theater level increase. Such results have been also gained from Gao et al. [14] and Clubley [15] researches, respectively. In the case of stress, all of the above statements are applied to all models except semi-filled slender tank. The water level has an effect of strain up to 90 percent (from $1.2 \mathrm{~m}$ decreases to $0.0827 \mathrm{~m}$ in a full broad tank).

A study that was done by Wang and Zhou [34] showed the positive effect of water which reduces the damage of tanks under blast loading. The main reason for that is because the water reduces the external pressure caused by blast loading. It is also observed that the external pressure by blast loading is reduced when the amount of water is increased. Since the external pressure caused by blast loading converts to the internal energy, there will be less pressure on the tanks, and as a result, there will also belles deformation and damage to the water tank.

It is also noticeable that the stresses at the intersection between shaft and tanks are higher than other parts of the water tanks, so this place is an important part of the elevated water tank that should be strengthened against blast loading. The reason that there is more stress on this part is due to the change in cross section as well as other critical parts Same results are also seen in Gao et al. [14], Clubley [15] and Zhou et al. [20] researches, respectively.

Fig. 13. Shows the representative failure process of the storage tank under blast. It can be observed, when the blast wave reaches the surface of the storage tank, the shaft (an area located in front of the explosion surface) is subjected to stress with plastic deformation. At the initial step of the failure, the maximum effective stress occurs at the connection of the shaft and the shell because of the effect of stress concentration. These results were founded in Paija and Vahora paper [29] as well.

As the blast wave spreads, the failure area moves upward, and the upper parts of the concrete elements gradually fall off, indicating the destruction of the structure of

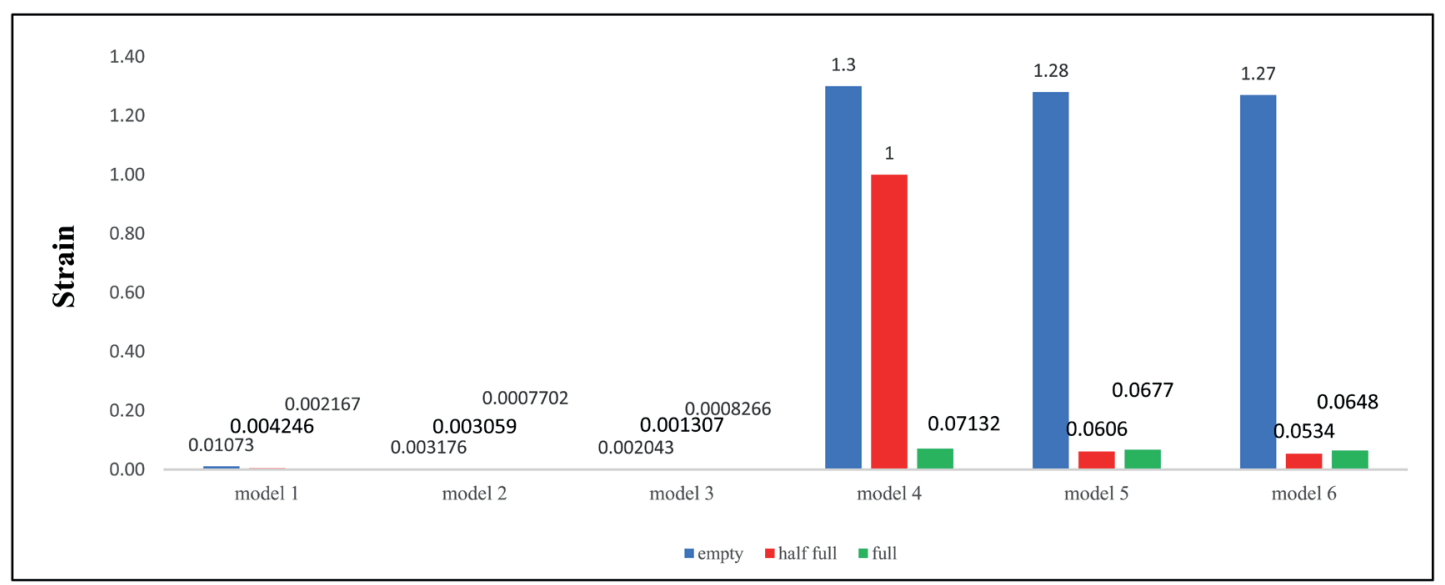

Fig. 12 Strain of water tanks 

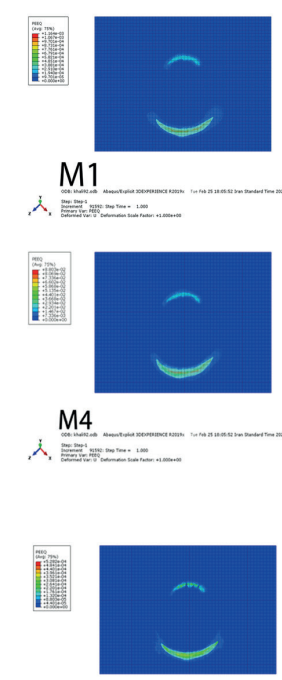

M1
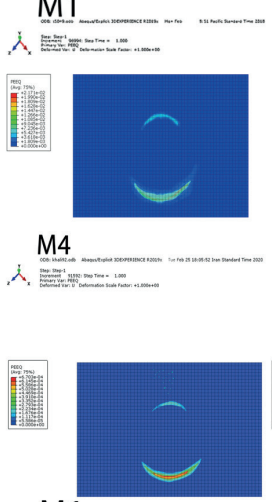

M1

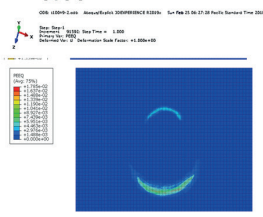

M4

$\lambda=$

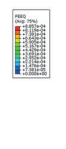

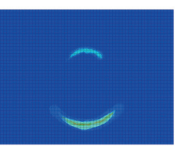

M2

y

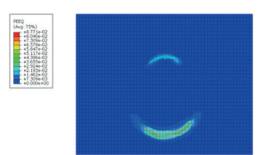

M5

I) empty of water

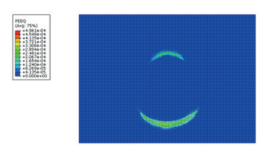

M2

$\dot{1}=$

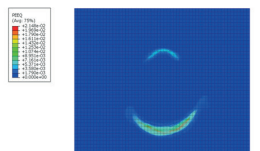

M5

$y=$

II) semi-full of water

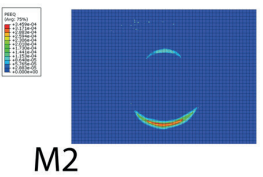

$M 2$

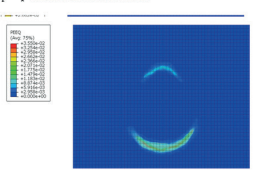

M5

$y=$

III) full of water $y=$

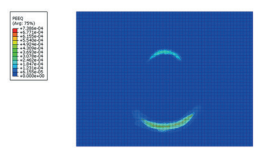

M3

$x_{2}=-1$

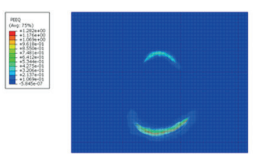

M6

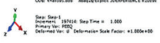

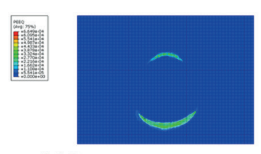

M3

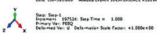

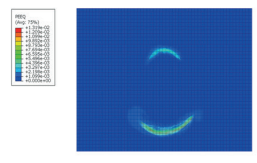

M6

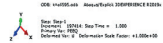

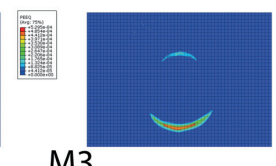

M3

$\lambda=$

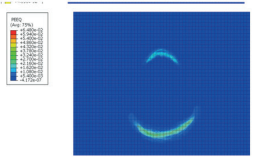

M6

$\lambda$

r blast loading

Fig. 13 Critical section of water tanks under blast loading

the outer parts of the water tank. This failure occurs on the central concrete elements of the outer wall facing the blast load. This can lead to leakage that was also seen in Duan research [35]. Therefore, it is necessary to use devices that can detect the leakage and immediately measures the tank area, to ensure the timely maintenance and rehabilitation of the water tank and also prevent human mistakes like fire and explosions. Also, it is necessary to control and prevent the tanks from a secondary explosion that causes damages.

\subsection{Force}

Fig. 14 shows the force-time curve under blast. It is seen that the highest force occurs at the beginning of the blast and it decreases with time. This is because of the
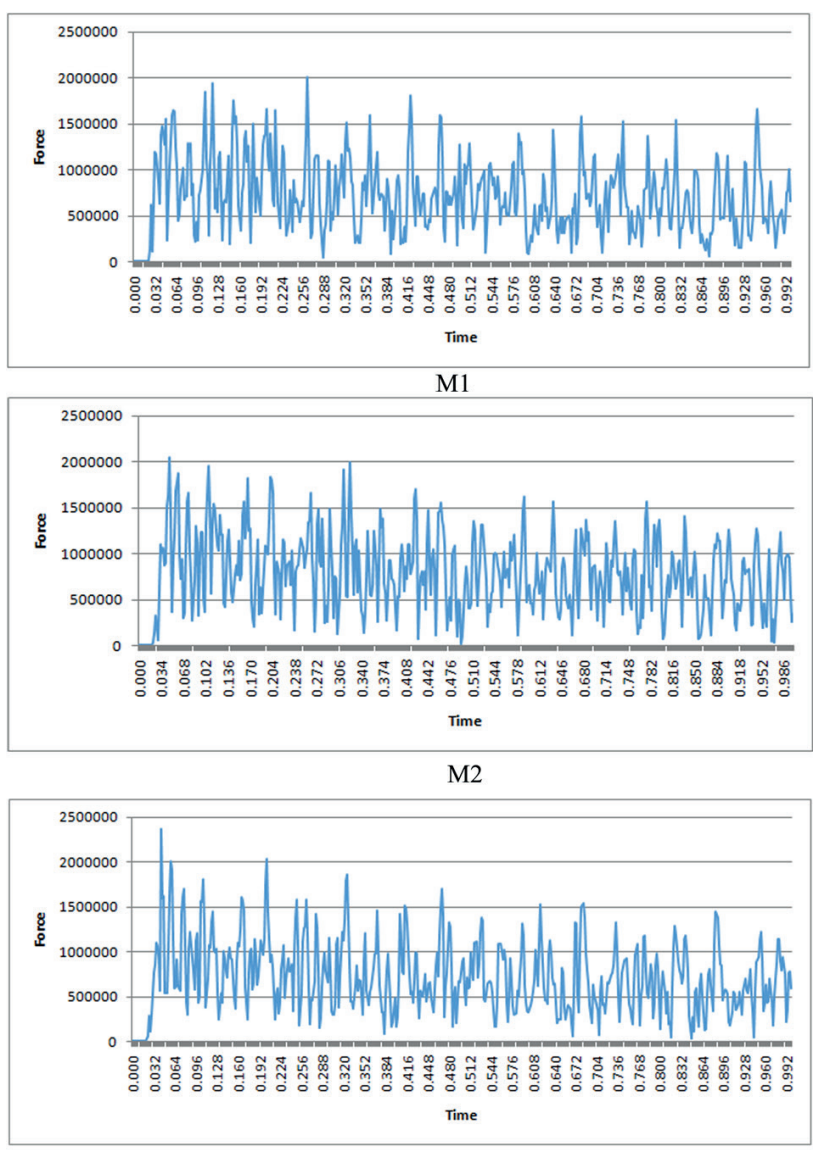

M3
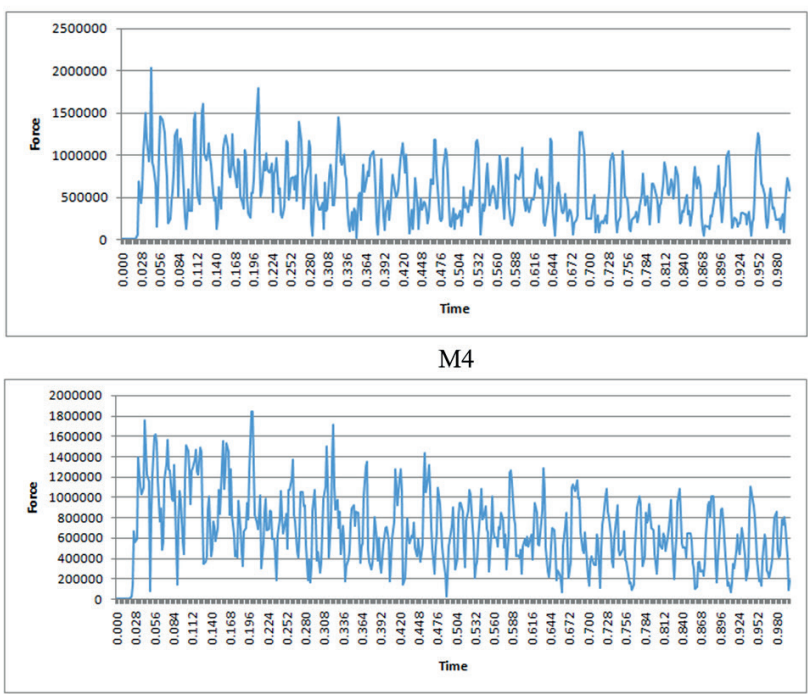

M5

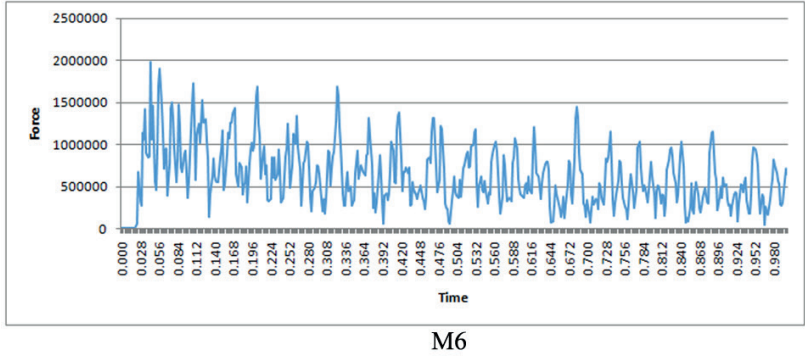

Fig. 14 Force-Time curves of full tanks 
impact effect and the impact characteristics of the blast wave. According to UFC and ASCE [31-33], after the rapid expansion of gas in the air under blast, incident wave instantly reaches the tanks and after reaching the peak value, it decreases exponentially. It is seen that in the M4-M5-M6 models, the forces are slightly less than in models M1-M2-M3. This phenomenon is because of the isolator. In a study done by Keramati and Nouri [36], Isolator models were clearly shown. In the study, the isolator decreases the forces, but in the current study because of the flexibility that the isolator brings, the forces approximately are the same. So, we can say that the structures with higher stiffness would behave better under blast loading in comparison with the flexible ones.

At the end of the study, it was observed that the incident wave was initially reflected as a regular wave and the wave was distorted in the region where viscous-in viscid interaction occurred like consequences Drikakis and Ofengeim study [37]. However, analyzing these effects is beyond the scope of our research, but it is recommended for future researches.

\section{Conclusions}

In this study, the three forms of water tanks such as slender, middle, and broad with three different levels of water (non-water, half water, and full water) were used to analyze the behavior of elevated water tanks under blast

\section{Reference}

[1] Shakib, H., Hosseini, M. "Analysis of elevated water concrete tanks under earthquake", Amirkabir Journal of Civil Engineering, 19, pp. 109-122, 1996. (in Persian)

[2] Hoskins, L. M., Jacobsen, L. S. "Water pressure in a tank caused by a simulated earthquake", Bulletin of the Seismological Society of America, 24(1), pp. 1-32, 1934. https://doi.org/10.1785/BSSA0240010001

[3] Graham, E. W., Rodriguez, A. M. "Characteristics of Fuel Motion Which Affect Airplane Dynamics", Journal of Applied Mechanics, 19(3), pp. 381-388, 1952. https://doi.org/10.1115/1.4010515

[4] Hamdan, F. H. "Design of Liquid Storage Tanks", Assessment of Eurocode 8-Part 4: European Seismic Design Practice, In: European Seismic Design Practice - Research and Application Proceedings of the 5th SECED conference, Chester, UK, 1995, pp. 521-529.

[5] Haroun, M. A. "Dynamic Analysis of Liquid Storage Tanks", California Institute of Technology, Pasadena, CA, USA, Rep. EERL80-4, 1980.

[6] Epstein, H. I. "Seismic Design of Liquid Storage Tanks", Journal of the Structural Division, 102(9), pp. 1659-1673, 1976. loading with and without LRB isolator. After using the Finite element method in Abaqus the following results have been obtained:

When the level of water increases up to $30 \%$, as a result of this the Sloshing level decrease.

Also, the decrease of aspect ratio leads to an increase in the Sloshing level.

Level of water can decrease the stress, strain, and the displacement of water and different parts of tanks (up to 90 percent) because it causes higher stiffness. And according to the results of the previous studies, the structures with higher stiffness would behave better than others under blast loading. So, the damage to the tanks would decrease as well.

While in broad tanks the displacements of water are higher in comparison with others models, these types of tanks are exposed to diamond shape and elephant foot buckling than others which lead to malfunction of the tanks.

The intersection structures between the shaft and elevated water tanks are a critical section. Therefore to retrofit the structures of these kinds of water tanks, they should be reinforced.

In all models, the displacement, sloashing height, stress, and strain with an isolator is higher than models without isolator. So, it can be said that the isolator has no good effect on the behavior of elevated water tanks under blast loading due to its flexibility which is up to $80 \%$.

[7] Melerski, E. S. "Numerical Analysis for Environmental Effects in Circular Tanks", Thin-Walled Structures, 40(7-8), pp. 703-727, 2002. https://doi.org/10.1016/S0263-8231(02)00021-6

[8] Kianoush, M. R., Chen, J. Z. "Effect of Vertical Acceleration on Response of Concrete Rectangular Liquid Storage Tanks", Engineering Structures, 28(5), pp. 704-715, 2006. https://doi.org/10.1016/j.engstruct.2005.09.022

[9] Alam, M. I., Fawzia, S., Zhao, X.-L., Remennikov, A. M. "Experimental Study on FRP Strengthented Stell Tubular Members under Lateral Impact", Journal of Composites for Construction, 21(5), pp. 1-14, 2017. https://doi.org/10.1061/(ASCE)CC.1943-5614.0000801

[10] Taylor, G. I. "The Use of Flat-Ended Projectiles for Determining Dynamic Yield Stress: I Theoretical Considerations", Proceedings of the Royal Society A, 194(1038), pp. 289-299, 1948. https://doi.org/10.1098/rspa.1948.0081

[11] Taylor, G. I. "The formation of a blast wave by a very intense explosion. II. The atomic explosion of 1945", Proceedings of the Royal Society A, 201(1065), pp. 175-187, 1950. https://doi.org/10.1098/rspa.1950.0050 
[12] Kalateh, F. "Dynamic failure analysis of concrete dams under air blast using coupled Euler-Lagrange finite element method", Frontiers of Structural and Civil Engineering, 13, pp. 15-37, 2019. https://doi.org/10.1007/s11709-018-0465-7

[13] Moradi, M., Aghajanzadeh, S. M., Mirzabozorg, H. Alimohammadi, M. "Underwater explosion and its effects on nonlinear behavior of an arch dam", Coupled Systems Mechanics, 7(3), pp. 333-351, 2018. https://doi.org/10.12989/csm.2018.7.3.333

[14] Gao, F., Ji, C., Long, Y., Song, K. "Dynamic responses and damages of water-filled cylindrical shell subjected to explosion impact laterally", Latin American Journal of Solids and Structures, 11(11), pp. 1924-1940, 2014. https://oi.org/10.1590/S1679-78252014001100003

[15] Clubley, S. K. "Long duration blast loading of cylindrical shell structures with variable fill level", Thin-Walled Struct, 85, pp. 234-249, 2014.

https://doi.org/10.1016/j.tws.2014.08.021

[16] Pandey, A. L., Kumar, R., Paul, D. K., Trikha, D. N. "Non-Linear Response of reinforced Concrete Containment Structure Under Blast Loading", Nuclear Engineering and Design, 236(9), pp. 9931002, 2006. https://doi.org/10.1016/j.nucengdes.2005.09.015

[17] Asgarpour, M. "Fluid-Structure-Soid Interaction Effects on Ground Concrete Tanks under Surface Blast", MSc Thesis, Malek Ashtar University of Technology, 2012. (In Persian)

[18] Chaman, M. H. "Retrofitting of Steel Oil Tanks to Blast Loadings", MSc Thesis, Malek Ashtar University of Technology, 2013. (in Persian)

[19] Rostaye, J. "Research, Study and Design Aboveground Steel Oil Tank under Explosive Loading", Research Activity, Malek Ashtar University of Technology, Iran, Tehran, 2012. (in Persian)

[20] Zhou, Y., Chong, J., Long, Y., Yu, Y., Li, Y., Wang, T. "Experimental studies on the deformation and damage of steel cylindrical shells subjected to double-explosion loading", Thin-Walled Structured, 127, pp. 469-482, 2018.

https://doi.org/10.1016/j.tws.2018.02.019

[21] Li, Y., Zhang, L., Dengbao, X., Zhao, T., Du, Z., Wu, W., Fang, D. "Experiment and numerical study on dynamic response of liquid cabin under internal blast loading", Thin-Walled Structures, 145, Article number: 106405, 2019.

https://doi.org/10.1016/j.tws.2019.106405

[22] Zhang. R., Jia, J., Wang, H., Guan, Y. "Shock Response Analysis of a Large LNG Storage Tank Under Blast Loads", KSCE Journal of Civil Engineering, 22, pp. 3419-3429, 2018. https://doi.org/10.1007/s12205-017-1246-x

[23] Chen, G., Wang, F., Zhou, C., Hu, K. "Dynamic Response Analysis of Large Arch-Roof Oil Tank Subjected to the Coupling Impact of Two-Source Blast Waves Based on Finite Element Method", Journal of Failure Analysis and Prevention, 20, pp. 333-347, 2020. https://doi.org/10.1007/s11668-020-00833-w
[24] Hafez, A. "Seismic Response of Ground-Supported Circular Concrete Tanks", PhD Thesis, Graguate School of Ryerson University, 2012.

[25] Dassault Systemes "Abaqus Finite Element Software", 2010. [online] Available at: https://www.3ds.com/

[26] Moslemi, M., Kianoush, M. R. "Parametric study on dynamic behavior of cylindrical ground-supported tanks", Engineering Structures, 42, pp. 214-230, 2012.

https://doi.org/10.1016/j.engstruct.2012.04.026

[27] US Army Corps of Engineers "UFC 3-340-02 Unified Facilities Criteria (UFC) Structures to Resist the Effects of Accidental Explosions", US Department of Defense, Washington, DC, USA, 2008.

[28] Prueter, P. E. "Using explicit finite element analysis to simulate blast loading on hazardous chemical storage tanks", presented at Simulia Community Conference, Providence, RI, USA, May, 20, 2014.

[29] Paija, S., Vahora, F. "Dynamic response and failure analysis of intze storage tanks under external blast loading", International Research Journal of Engineering and Technology, 4(11), pp. 1-6, 2017. [online] Available at: https://www.irjet.net/archives/V4/i11/ IRJET-V4I1101.pdf

[30] Pandurangan, B. "Development, Parametrization and Validation of Dynamic Material Models for Soil and Transparent Armor Glass", PhD Thesis, Graduate School of Clemson University, 2009.

[31] US Army Corps of Engineers "UFC 3-340-02 Structures To Resist The Effects Of Accidental Explosions, US Department of Defense", Washington, DC, USA, 2008.

[32] Bounds, W. L. "Design of Blast-Resistant Buildings in Petrochemical Facilities", American Society of Civil Engineers, Reston, VA, USA, 2010. https://doi.org/10.1061/9780784410882

[33] ASCE "Blast Protection of Buildings (59-11)", American Society of Civil Engineers, Reston, VA, USA, 2011.

[34] Wang, Y., Zhou, H. "Numerical study of water tank under blast loading", Thin-Walled Structures, 90, pp. 42-48, 2015. https://doi.org/10.1016/j.tws.2015.01.012

[35] Duan, H. "A Leakage and Explosion Hazard Analysis on Dalian Liquid Natural Gas Station", Journal of Chinese People's Armed Police Force Academy, 28(4), pp. 36-38, 2012.

[36] Keramati, A., Nouri, G. R. "Effect of behavioral parameters of base isolators on the seismic response of the bridge to near-fault ground motion", AUT Journal of Civil Engineering, 4(3), pp. 1-11, 2019. https://doi.org/10.22060/AJCE.2019.15899.5554

[37] Drikakis, D., Ofengeim, D. "Computation of non-stationary shock wave/cylinder interaction using adaptive-girds methods", Journal of Fluids and Structures, 11(6), pp. 665-691, 1997. https://doi.org/10.1006/jfls.1997.0101 